Aike Beckmann - Ralph Timmermann

Adriene F. Pereira - Christian Mohn

\title{
The effect of flow at Maud Rise on the sea-ice cover - numerical experiments
}

Received: 31 March 2001 / Accepted: 13 July 2001

\begin{abstract}
The role of seamounts in the formation and evolution of sea ice is investigated in a series of numerical experiments with a coupled sea ice-ocean model. Bottom topography, stratification and forcing are configured for the Maud Rise region in the Weddell Sea. The specific flow regime that develops at the seamount as the combined response to steady and tidal forcing consists of free and trapped waves and a vortex cap, which is caused by mean flow and tidal flow rectification. The enhanced variability through tidal motion in particular modifies the mixed layer above the seamount enough to delay and reduce sea-ice formation throughout the winter. The induced sea-ice anomaly spreads and moves westward and affects an area of several $100000 \mathrm{~km}^{2}$. Process studies reveal the complex interaction between wind, steady and periodic ocean currents: all three are required in the process of generation of the sea ice and mixed layer anomalies (mainly through tidal flow), their detachment from the topography (caused by steady oceanic flow) and the westward translation of the sea-ice anomaly (driven by the timemean wind).
\end{abstract}

Keywords Maud Rise · Polynya - Ice-ocean modelling $\cdot$ Tides $\cdot$ Seamounts

\section{Introduction}

The occurrence of the so-called Weddell Polynya is one of the intriguing phenomena of Antarctic climate research. According to remote sensing data, an area of about $300000 \mathrm{~km}^{2}$ between $64^{\circ} \mathrm{S}$ and $69^{\circ} \mathrm{S}$ near the Greenwich meridian was essentially ice-free (with ice

Responsible Editor: Dirk Olbers

A. Beckmann ( $\square) \cdot$ R. Timmermann · A. F. Pereira · C. Mohn Alfred Wegener Institute for Polar and Marine Research, PO Box 120161, 27515 Bremerhaven, Germany

e-mail: beckmann@awi-bremerhaven.de concentrations not exceeding $15 \%$ ) through the entire winters of 1974-1976, while the surrounding area was almost completly ice-covered (Carsey 1980). During its 3-year lifetime, the polynya shifted westward with a mean velocity of about $1 \mathrm{~cm} \mathrm{~s}^{-1}$, which is consistent with the large-scale ocean currents in this region. The polynya was associated with intense air-sea interaction, leading to substantial deep-water cooling during and after the polynya's occurrence (Gordon 1982).

The circumstances of its formation, the mechanisms for its maintenance and the large-scale consequences of this phenomenon are still poorly understood. A number of plausible hypotheses have been put forward:

- Atmospheric wind and temperature anomalies: while the effect of ice export due to a divergent wind field was found to be insufficient (Martinson et al. 1981), the advection of anomalously warm air was recently suggested to be a contributing factor (van den Broeke 2000);

- Oceanic mixed-layer thickness and temperature anomalies: an unusually shallow mixed layer, related to localized upwelling, has been considered as a possible mechanism for triggering deep convection (Martinson et al. 1981). Large warm subsurface eddies that were dected by Gordon and Huber (1984) support this idea.

- Coupled ice-ocean studies: Lemke (1987) proposed that the combination of a divergent sea-ice drift and pycnocline upwelling can induce the formation of a polynya by positive feedback, even in three subsequent years. This has been investigated in a simplified coupled atmosphere-sea ice process study (Timmermann et al. 1999). Recent coupled climate model simulations revealed strong sensitivities of polynya formation to precipitation (Marsland and Wolff 2001) and the convection parameterization (Kim and Stössel 2001).

Conclusive evidence is lacking, partly because no in situ observations have been carried out and because the Weddell Polynya has not formed again since the 
mid-1970s. In most cases, however, it has been assumed that the upwelling may be related to Maud Rise, a large submarine bank at $2^{\circ} 30^{\prime} \mathrm{E}, 65^{\circ} \mathrm{S}$ (Gordon and Huber 1984; Martinson 1990; Muench et al. 2001). It is therefore surprising that no detailed numerical study was devoted to the effect of Maud Rise on the coupled sea ice-ocean system. This study tries to fill this gap.

Recently, the availability of atmospheric reanalysis data has led to a number of independent sea ice-ocean hindcasts of the past decades. These data should, in principle, contain at least part of the signature of the Weddell Polynya. Although none of the simulations succeeded in reproducing the polynya, the 40-year integration of Beckmann and Timmermann (2001), using data from the NCEP reanalysis, has shown some thinning of the sea-ice cover west of Maud Rise in the years 1975 and 1976 (Fig. 1). It would be an exaggeration to call this a polynya, but it is the first simulation that shows a clear tendency of the right sign at the right time in the right region. Beckmann and Timmermann (2001) identified an interdecadal propagating wave pattern around Antarctica which might be connected to the occurrence of the Weddell Polynya.

In general, however, the results of coarse resolution coupled sea ice-ocean models are not robust enough to unambiguously point to (or rule out) a certain mechanism; this might be due to a number of factors:

- Insufficient resolution (leading to reduced variability and poor representation of topography) along with inadequate parameterizations of subgrid-scale processes and ice-ocean interaction.

- Systematic errors in the atmospheric forcing fields (or feedbacks).

- The omission of an oceanic process, which contributes to both circulation and mixing at steep topography: the tides.

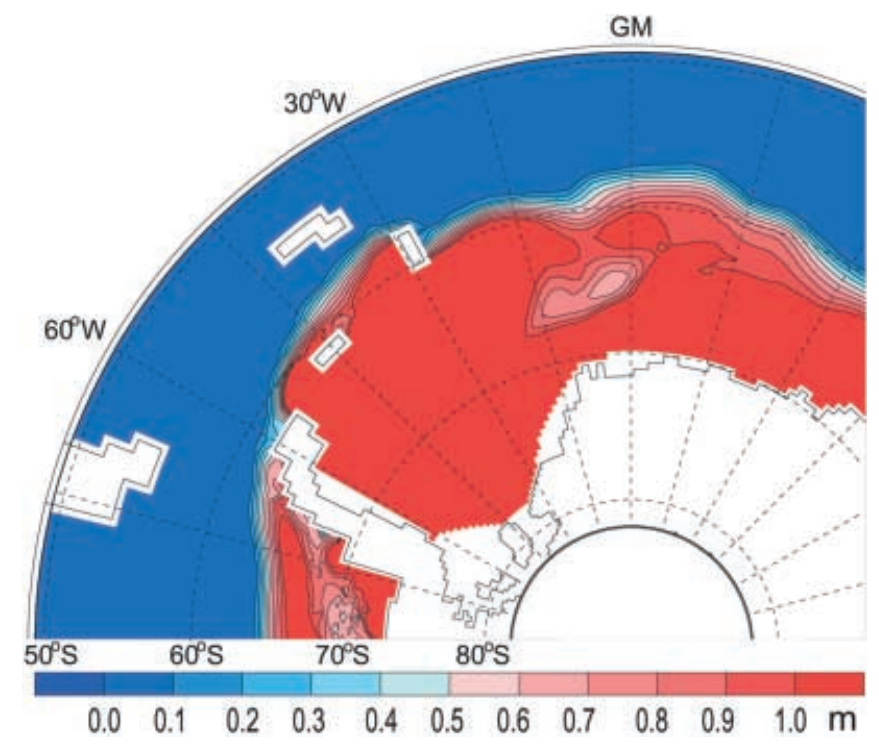

Fig. 1 Weddell Sea 1975 September sea-ice thickness in the BRIOS-2/ NCEP experiment (After Beckmann and Timmermann 2001)
Within the BRIOS (Bremerhaven Regional Ice Ocean Simulations; Beckmann et al. 1999) framework, coupled ice-ocean models have been developed to investigate the large-scale circulation and water mass transformation processes in the Weddell Sea (Timmermann et al. 2001). In this study we apply a member of this model family in a process study of sea ice-ocean interaction at Maud Rise.

The paper is organized as follows: sect. 2 briefly reviews our knowledge of flow at seamounts, followed by a description of the hydrographic situation at Maud Rise in sect. 3. Section 4 introduces the coupled sea iceocean model, and its adaptation to the problem. Section 5 describes the reference experiment with focus on the evolution of the oceanic mixed layer and sea-ice cover. Some of the processes and their parameter sensitivities are then investigated in sect. 6. Conclusions are summarized in sect. 7 , followed by an outlook to future research activities in sect. 8 .

\section{Flow at seamounts}

\subsection{Observations}

Seamounts, submarine hills of at least $1000 \mathrm{~m}$ height above the deep-sea floor, are known to have a significant influence on the ocean circulation in their immediate vicinity. Hydrographic measurements at isolated topography have detected a pronounced doming of the isopycnals above many seamounts. Probably the first observation of uplifted isopycnals above a seamount was reported by Defant (1940) from the Altair Seamount in the North Atlantic. More recent studies confirm the ubiquitous existence of such density anomalies and point out that there must be a corresponding anticyclonic flow about them (Meincke 1971; Vastano and Warren 1976; Genin and Boehlert 1985; Roden 1987; Genin et al. 1989; Bersch et al. 1992). This closed circulation is referred to as a Taylor cap, the generalization of the well-known Taylor column in a stratified fluid.

Strong currents and a generally enhanced variability are also observed at many seamounts. The flow amplification is often directly related to tidal forcing; amplified currents of diurnal frequency have, for example, been identified by Huthnance (1974), Hunkins (1986), Genin et al. (1989), Eriksen (1991), and Codiga and Eriksen (1997). At the same time, the strong currents at seamounts are associated with enhanced levels of local turbulence and vertical/diapycnal mixing (Eriksen 1998). Observed values of vertical diffusivities in the vicinity of seamounts are 10-100 times larger than the oceanic background values (Kunze and Toole 1997).

As obstacles in the path of large-scale flow, seamounts can cause current deflections, wakes, a meandering (leeside Rossby waves) occasionally accompanied by eddy formation, thus increasing the downstream variability 
(see Hogg 1980 for an overview). Such downstream effects of seamounts in the path of strong (boundary) currents were reported by Roden and Taft (1985) for the Kuroshio and Vastano and Warren (1976) for the Gulf Stream; the deflections and modifications have been confirmed by Richardson (1981) and Cornillon (1986) using surface drifting buoys and satellite imagery, respectively.

\subsection{Theoretical and modelling studies}

In recent years, the observational material (and multidisciplinary interest) has motivated a number of theoretical, laboratory and numerical studies on flow at isolated seamounts.

Chapman (1989) and Brink (1989, 1990) considered the response to oscillatory forcing, and found that seamounts are capable of supporting seamount-trapped waves, which are strongly bottom-trapped and propagate anticyclonically about the seamount. The intensity of the current field depends strongly on rotation and stratification, but can reach up to 100 -fold amplification of the forcing amplitude.

In addition to several laboratory studies (Boyer and Zhang 1990; Codiga 1993; Zhang and Boyer 1993), the problem of flow at tall and steep seamounts (the detachment of cyclonic eddies and the formation of Taylor caps in steady flows (Chapman and Haidvogel 1992), the resonant generation of seamount-trapped waves, and the generation of a time-mean residual circulation about the seamount (Haidvogel et al. 1993)) has been investigated with primitive equation models with terrain-following vertical coordinates. Forced by barotropic diurnal tidal currents, substantial amplification was found for a wide range of parameters; the local response is a seamount-trapped wave with the shape of a dipole. Tidal rectified fluxes of heat and salt create a strong positive density anomaly above the seamount, inducing a cyclogeostrophically balanced prograde (i.e. in the direction of freely propagating waves) time-mean flow, closely trapped to the bottom. The buildup of this anomaly is balanced by a time-mean secondary circulation in the vertical/radial plane, characterized by persistent downwelling over the top of the seamount at all depths and a radially outward flow at the bottom.

Most of these results were obtained from process studies with idealized configurations (circular seamount, linear or exponential stratification), and exploration of the parameter space in various directions (influence of rotation and stratification - the Burger number; seamount geometry - fractional seamount height, radius, steepness, orientation). A quantitatively realistic simulation of these phenomena was carried out by Beckmann and Haidvogel (1997), who modelled flow around Fieberling Guyot and were able to reproduce the observed wave amplification by a factor of 20 and the rectification of $10 \mathrm{~cm} \mathrm{~s}^{-1}$ (Brink 1995; Kunze and Toole 1997) found during the TOPO project.
The effects of a seamount on the mixed layer in high latitudes have been investigated by Alverson and Owens (1996) and Alverson (1997), who used a similarly configured model, and applied buoyancy forcing to study the topographic preconditioning for open ocean convection. In their density-only simulations, the topography introduces a spatial inhomogeneity that will lead to deeper convection above the seamount's upstream flank, where the upwelling dense water merges with the surface mixed layer.

To summarize, the effects of seamounts on the circulation and thermohaline structure of the upper ocean can be significant: localized up- and downwelling and increased mixing due to both steady and oscillatory impinging currents will lead to a spatial inhomogeneity of the mid- to upper-level hydrography and flow field; anomalies may even detach and propagate downstream.

It seems plausible (see, e.g. Muench et al. 2001) that significant, even large-scale, consequences of flow around topography can be found at Maud Rise. Several of the described mechanisms may play a role, and as a consequence of their interplay, the sea-ice thickness and distribution on a much larger scale may be affected.

\section{Hydrography, circulation and tides near Maud Rise}

Maud Rise is one of the most extensive isolated anomalies of the deep-sea morphology in the Southern Ocean. It covers an area of approximately 300 by $400 \mathrm{~km}$ and is centered at $65^{\circ} \mathrm{S}$ and $2^{\circ} 30^{\prime} \mathrm{E}$. Roughly $500 \mathrm{~km}$ from the Antarctic coast, it rises about $3500 \mathrm{~m}$ above the Weddell Abyssal Plain to a minimum depth of $1700 \mathrm{~m}$ (Smith and Sandwell 1997) and is characterized by a pronounced asymmetry. The main complex is a ridge-like feature with an elliptic plateau with an average depth of $2000 \mathrm{~m}$, which is accompanied by relatively small, but distinctive irregularities to the east and south (Fig. 2). The average slope of the flanks is in the order of $2 \%$, the maximum slope is up to $6 \%$.

Based on observations in this region (Bersch et al. 1992; Schröder and Fahrbach 1999; Muench et al. 2001), we present a schematic distribution of the upper water masses in the vicinity of Maud Rise (Fig. 3). Compared to midlatitudes, the stratification is weak and characterized by a pronounced subsurface temperature maximum. This $T_{\max }$ surface marks the uppermost layer of the deep water in the Weddell Gyre and forms the base of the mixed layer. South of Maud Rise the $T_{\max }$ is accompanied by oxygen and nutrient minima, which characterize upper lower circumpolar deep water (LCDW), found in 200-600 $\mathrm{m}$ depth. North of Maud Rise, central intermediate water (CIW) is found in almost the same depth interval. CIW represents the oxygen minimum intermediate layer of the central Weddell Gyre and can be distinguished from LCDW by its nutrient maximum (Whitworth and Nowlin 1987). Above the summit of Maud Rise LCDW and CIW are separated by the topographically induced doming of the 


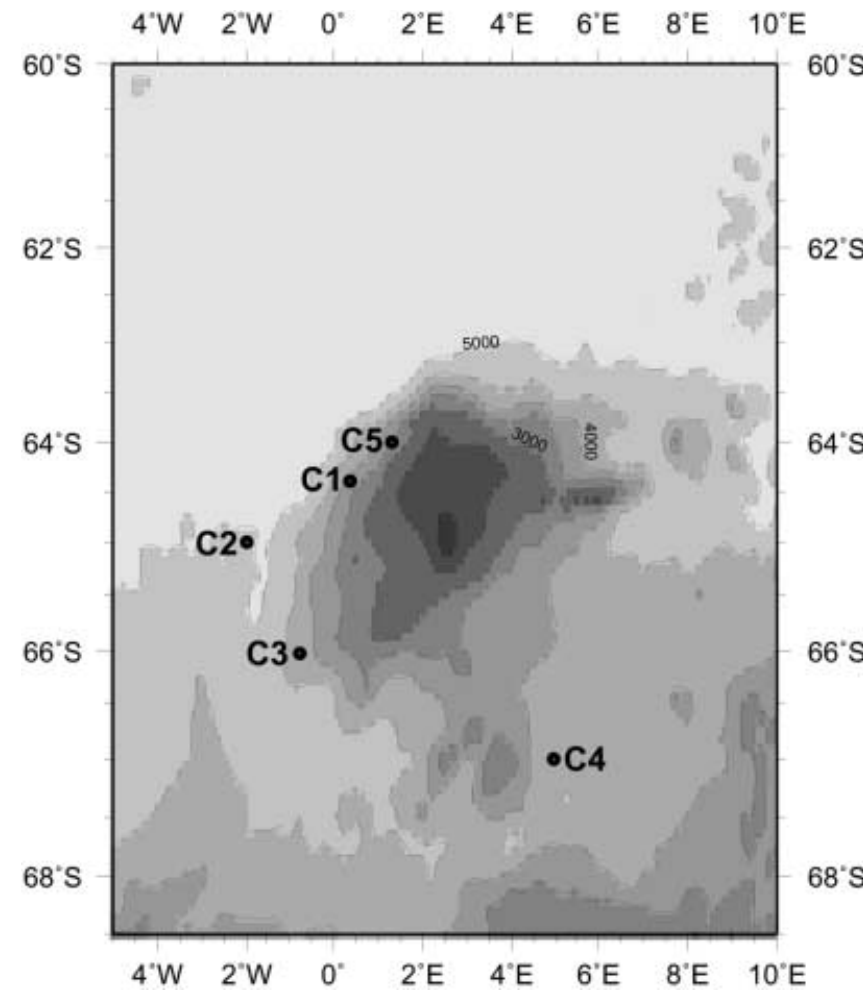

Fig. 2 Topography in the Maud Rise area from Smith and Sandwell (1997). Contour interval $500 \mathrm{~m}$. The locations of current meters used for tidal analysis in sect. 3 are indicated

mass field, introducing Maud Rise deep water (MRDW) of low temperature and salinity, but high oxygen and nutrient concentrations to depths of about $600 \mathrm{~m}$. The amplitude of the doming can reach about $500 \mathrm{~m}$ in middepths, but is strongly reduced near the surface due to the increase of the horizontal salinity gradient (Bersch et al. 1992).

Bersch et al. (1992) found that the cold-core anomaly induced by Maud Rise has a diameter of about 150$200 \mathrm{~km}$ and persists throughout the year. They suggest the existence of a Taylor cap circulation. In a recent study, Muench et al. (2001) combine observations and model results to show that warm water is transported anticyclonically around the cold, stagnant core above Maud Rise.

The large-scale circulation in this area is dominated by westward flow across Maud Rise. Between 1989 and 1994 Schröder and Fahrbach (1999) observed two current branches north and south of the seamount, separated by the cold water column on top of Maud Rise. Based on geostrophic calculations, they estimated a total westward transport of $\approx 18 \mathrm{~Sv}$, the northern branch carrying $14 \mathrm{~Sv}$ and the southern branch $4 \mathrm{~Sv}$, consistent with a generally anticyclonic flow around the rise. These values amount to roughly $1 \mathrm{~cm} \mathrm{~s}^{-1}$ barotropic flow to the (south-)west.

In addition to the effects on steady flow, Maud Rise also modifies tidal motion locally. To our knowledge, no systematic observational study of tides in the Maud Rise

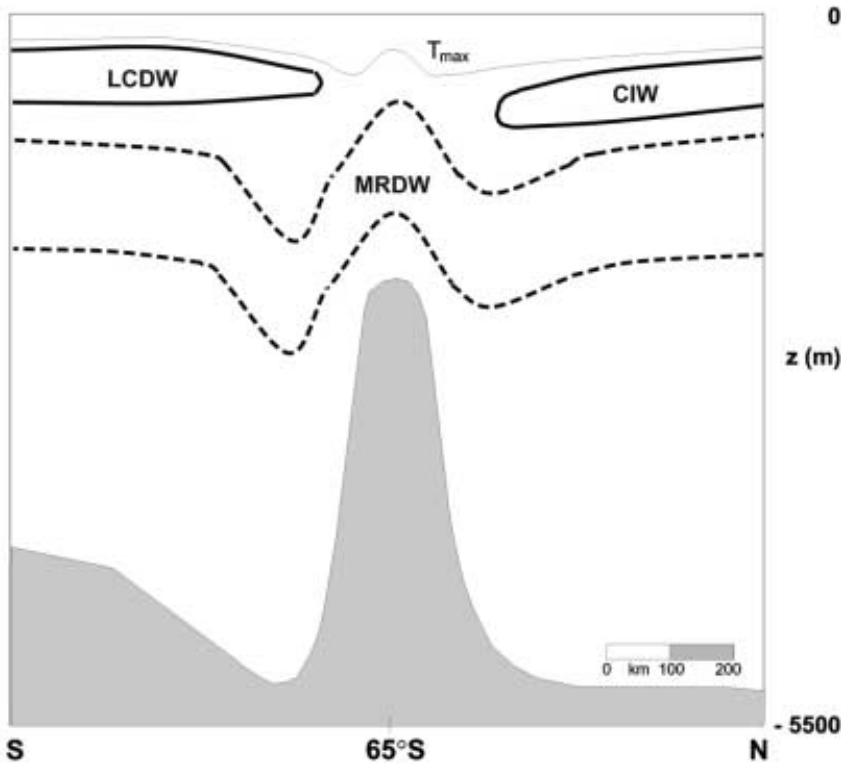

Fig. 3 Schematic distribution of upper-layer water masses at Maud Rise

area has been carried out. The few existing records of moored current meters capture the tidal currents along the flanks of the bank; however, no far-field measurements are available. Therefore, numerical models are necessary to provide a coherent and spatially dense picture of the tidal regime at and around Maud Rise. Global tidal models (see Andersen et al. 1995, for a list) have a coarse resolution (maximum resolution of $0.5^{\circ}$ by $0.5^{\circ}$ ) and are not able to reproduce small-scale topographic features of the seamount. Regional models like those of Genco et al. (1994) and Robertson et al. (1998), with their finer resolution $\left(1 / 6^{\circ}\right.$ in longitude and $1 / 12^{\circ}$ in latitude for the latter study), did not specifically focus on the Maud Rise region.

In order to obtain a reliable quantitative picture of the magnitude and direction of tidal currents for our study, we employed our BRIOS barotropic tidal model. The model is based on the non-linear depth-averaged shallow-water equations, and includes the astronomical forcing with standard corrections for tidal loading and ocean self-attraction. It is applied to the Weddell Sea from $83^{\circ} \mathrm{S}$ to $56^{\circ} \mathrm{S}$ and from $80.65^{\circ} \mathrm{W}$ to $12^{\circ} \mathrm{E}$. The grid resolution is isotropic $\left(0.25^{\circ}\right.$ in the zonal, $0.25^{\circ} \cos \phi$ in the meridional direction) and, in the region shown in Fig. 2, varies between 10 and $12 \mathrm{~km}$. The model is forced at the open boundaries with time series of freesurface elevation for the four main frequencies $\mathrm{M}_{2}, \mathrm{~S}_{2}$, $\mathrm{K}_{1}$ and $\mathrm{O}_{1}$ computed from the inverse global tidal model TPXO.2 (Egbert et al. 1994).

Figure 4 compares modelled and observed (Bersch et al. 1992) tidal ellipses at the five locations shown in Fig. 2. The observed tidal ellipses are the mean of all the current meters (in varying depths) at one site. The correspondence between model and observation is very good for diurnal frequencies. Larger discrepancies 
Fig. 4 The current ellipses for the four tidal frequencies at sites $C 1, C 2, C 3, C 4$ and $C 5$. The line within each ellipse denotes the Greenwich phase and the arrow denotes the sense of rotation. Solid line ellipses are observed data (Bersch et al. 1992; kindly provided by B. Huber), dashed line ellipses are model results. Local water depth at the mooring and in the model are listed for each location

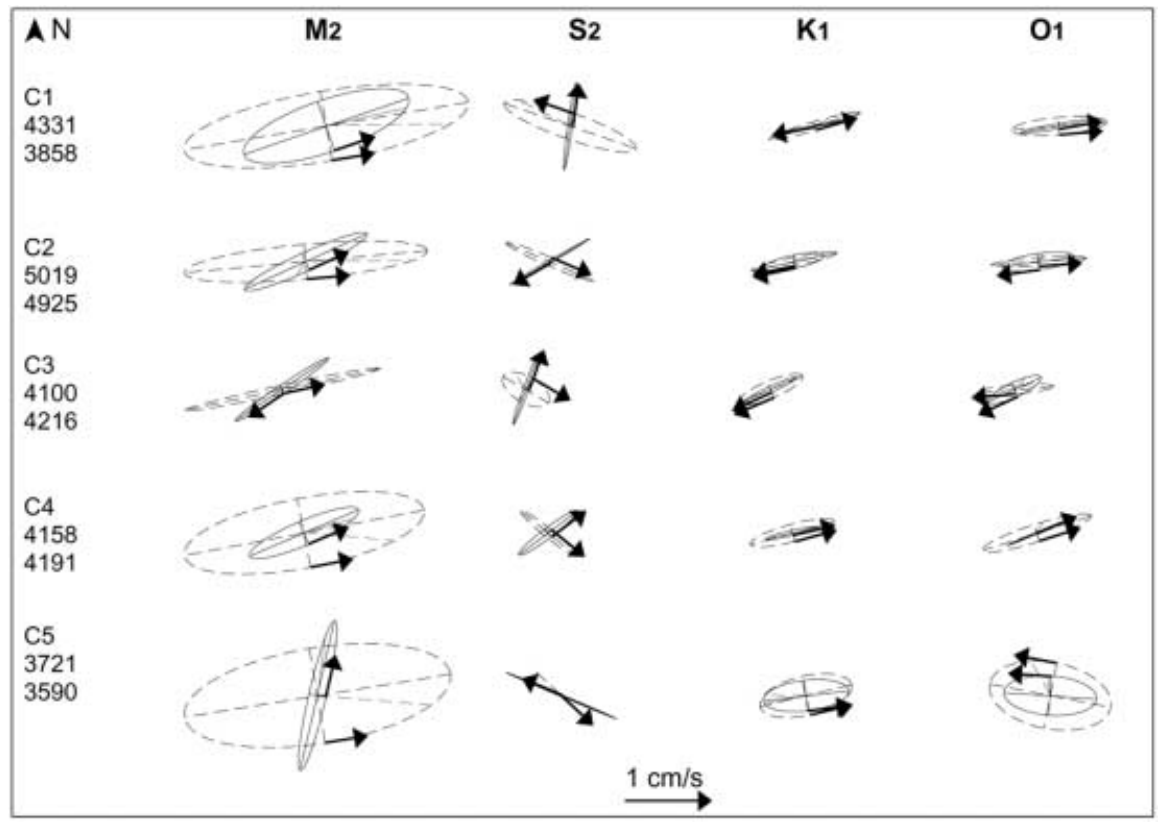

(an overestimation of amplitudes for $\mathbf{M}_{2}$ and a $90^{\circ}$ difference in ellipse inclination for $\mathrm{S}_{2}$ ) are evident in the semidiurnal band. Possible reasons for this are inaccurate model bathymetry and/or baroclinic effects which are not included in the model. Despite these differences, the shape of the ellipse is well represented even for the semidiurnal band.

The computed $\mathrm{O}_{1}$ and $\mathrm{M}_{2}$ tidal current ellipses are shown in Fig. 5. For both frequencies, the flow in the deep ocean is mainly east-west, while they are more circular on top of Maud Rise. Typical far-field diurnal $\left(\mathrm{O}_{1}\right)$ and semidiurnal $\left(\mathrm{M}_{2}\right)$ currents are $1.2 \mathrm{~cm} \mathrm{~s}^{-1}$ and $2.5 \mathrm{~cm} \mathrm{~s}^{-1}$, respectively. The moderate amplification at Maud Rise leads to about $6 \mathrm{~cm} \mathrm{~s}^{-1}$ for $\mathrm{M}_{2}$ and about $3 \mathrm{~cm} \mathrm{~s}^{-1}$ for $\mathrm{O}_{1}$. Similar results are found for $\mathrm{K}_{1}$. Farfield $\mathrm{S}_{2}$ currents are $1.0 \mathrm{~cm} \mathrm{~s}^{-1}$ and due the existence of a current-amphidromic point near $4.5^{\circ} \mathrm{W}, 63.5^{\circ} \mathrm{S}$, the ellipse inclination is mainly aligned northwest-southeast. We will use these model results as the basis for the far-field forcing of our Maud Rise experiments.

\section{The coupled sea ice-ocean model}

\subsection{Experimental strategy}

The goal of this study is to systematically investigate the effect of Maud Rise on the coupled sea ice-ocean system by applying state-of-the-art numerical models. Our philosophy here is to use as many realistic ingredients as necessary, while using a simplified approach wherever possible, to clearly identify the effect of the topography. We therefore use realistic stratification, a fully nonlinear equation of state (UNESCO 1981; modified by Jackett and McDougall (1995) for use with potential rather than in situ temperatures), realistic topography and flow amplitudes (steady and tidal). Other aspects like the spatial and temporal dependence of the forcing are idealized: the steady flow is unidirectional and the tidal forcing is restricted to one diurnal and one semidiurnal frequency. The atmospheric forcing is also assumed to be uniform, such that any inhomogeneity in ocean circulation and mixing, sea-ice dynamics and thermodynamics can be unambiguously related to the topography. To exclude the effects of the coast (Ekman divergence, coastal polynyas) we use a double periodic domain, which allows us to include wind without disturbing effects of model boundaries.

\subsection{The numerical tools}

\subsubsection{Ocean component}

The ocean component of the BRIOS coupled ice-ocean model is based on the S-coordinate primitive equation model SPEM (Haidvogel et al. 1991). Configured for applications in the Antarctic circumpolar ocean, it has been used in both stand-alone and coupled versions to study the large-scale circulation and water-mass distribution in the Weddell Sea (Beckmann et al. 1999; Timmermann et al. 2001). Separate studies on the optimal choice of subgrid-scale parameterizations have led to a selection of adaptive mixing schemes, that were found to be essential in keeping the simulated hydrography close to observations: the Pacanowski and Philander (1981) mixing scheme ensures that vertical mixing is continuously increased for a weakening stratification. To avoid unrealistic deep convection in the central Weddell Sea, the vertical diffusivity is limited by a maximum value of $0.01 \mathrm{~m}^{2} \mathrm{~s}^{-1}$. 
(a) $\mathrm{M}_{2}$

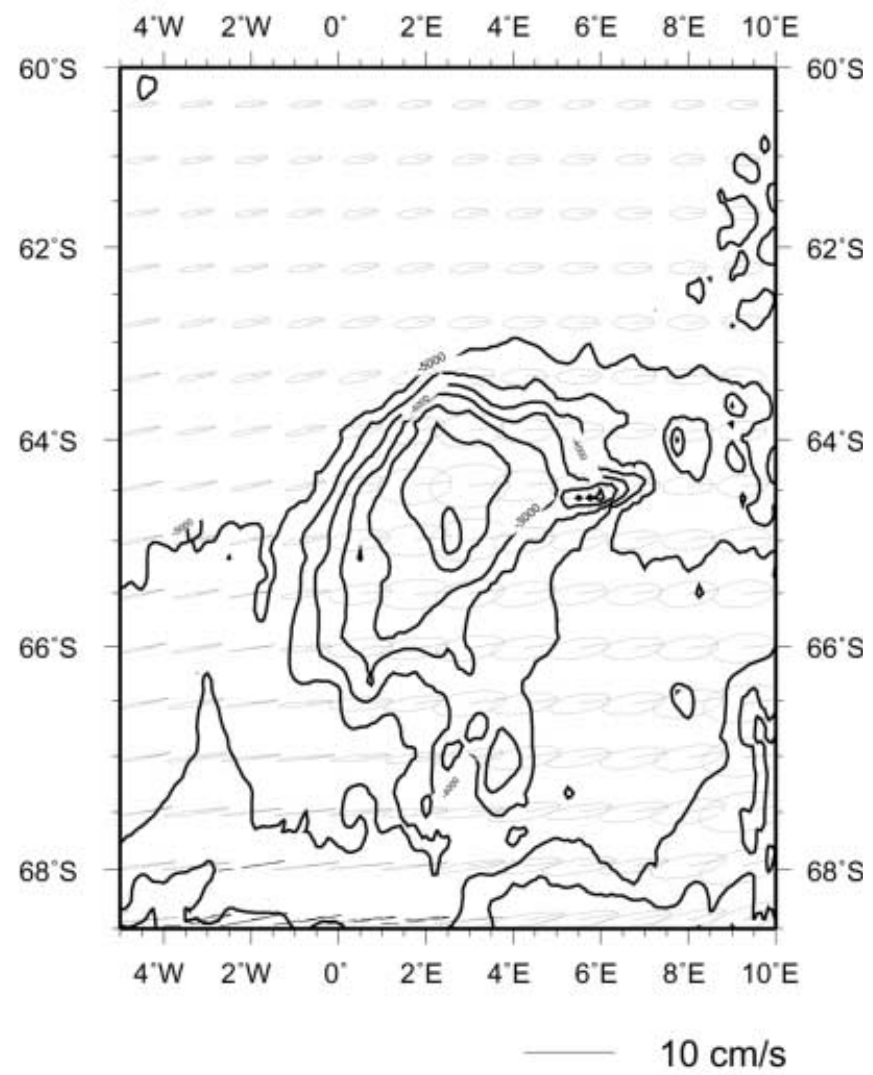

(b) $\mathrm{O}_{1}$

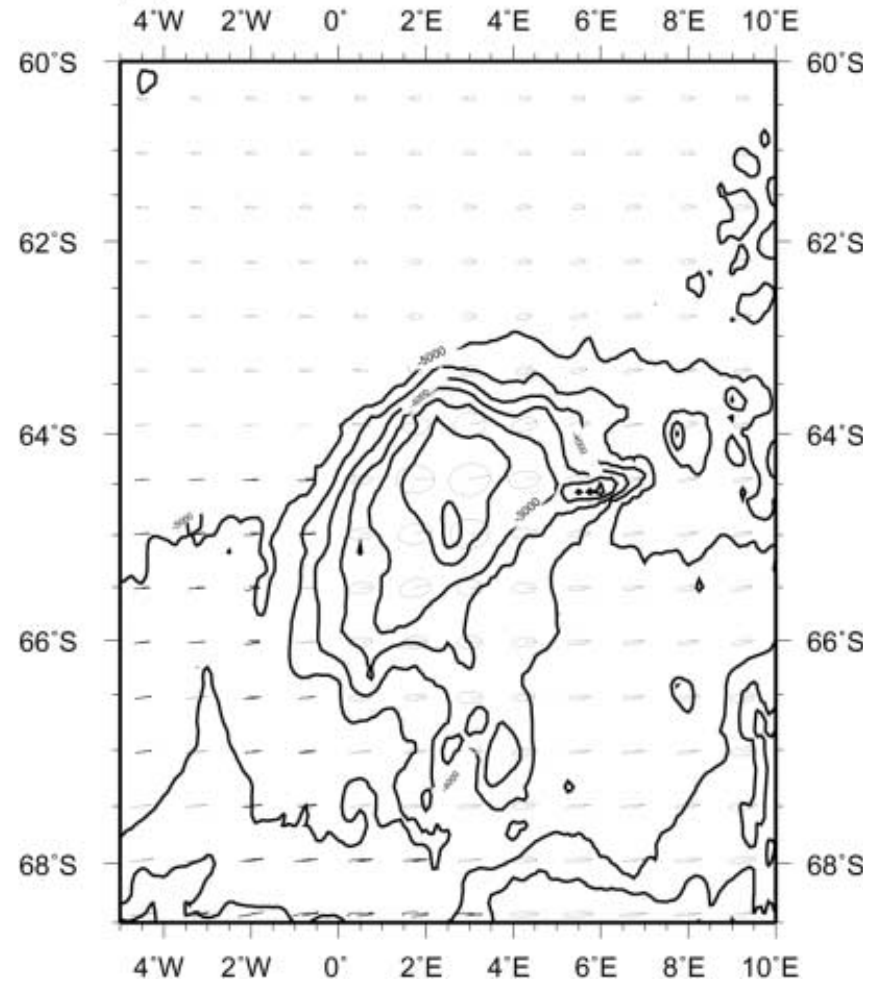

Fig. 5 Computed current ellipses for $\mathrm{M}_{2}$ and $\mathrm{O}_{1}$. Solid (dashed) ellipses rotate counterclockwise (clockwise)
For the present study, harmonic lateral diffusion, rotated to geopotential surfaces, has been adopted for all prognostic variables: the eddy coefficients are Reynolds number-dependent but do not exceed $200 \mathrm{~m}^{2}$ $\mathrm{s}^{-1}$. For numerical stability, the lateral viscosity has been set to $10000 \mathrm{~m}^{2} \mathrm{~s}^{-1}$. In contrast to many previous process studies of flow at seamounts, mixing does not operate only on the deviations from climatology but on the total tracer field. The sink of energy at the bottom is parameterized by a quadratic function of lowest layer velocities.

\subsubsection{Sea ice component and coupling}

The ice component of the BRIOS model family is a dynamic-thermodynamic sea-ice model with a viscousplastic rheology (Hibler 1979) and the Parkinson and Washington (1979) thermodynamics using the Semtner (1976) zero-layer approach for heat conduction. Ice and ocean model communicate through the exchange of heat, freshwater (salt) and momentum. The details of model coupling (which include a velocity-dependent ice-ocean heat flux and a $10^{\circ}$ turning angle for the ice-ocean surface stress) can be found in Timmermann et al. (2001).

Since horizontal and vertical near-surface resolution are comparable to the circumpolar model version, most of the parameter setting could be adopted directly. Exceptions are the ice momentum advection, which is excluded from BRIOS-2 (and most other large-scale sea ice models) but is retained here, and the removal of the lower limit of vertical mixing in the near-surface layers, that had been found necessary for stability of multi-year integrations. In addition to that, we now use synchronous time-stepping to ensure immediate feedbacks between the ice and ocean fields.

\subsection{Model configuration}

\subsubsection{Domain and grid}

The seamount is placed in the center of a double periodic domain (Fig. 6). The Maud Rise topography (Smith and Sandwell 1997) has been modified outside the seamount area to conform to the periodicity conditions. The external dimensions of the domain $(2880 \mathrm{~km}$ long $\times 2880 \mathrm{~km}$ wide) are more than seven times the diameter of the seamount. This proves to be sufficient to eliminate the influence of the periodicity assumption on the dynamics in the vicinity of the seamount, at least for integration periods of a few months. The grid spacing of $15 \mathrm{~km}$ is sufficient to resolve the horizontal scales set by topographic slope and trapped waves. The internal Rossby radius of deformation $R_{D}$ is about $4 \mathrm{~km}$; the corresponding horizontal scales at $2 \pi R_{D}$ are marginally resolved by the grid. It should be emphasized that horizontal model resolution is not our primary concern; our 


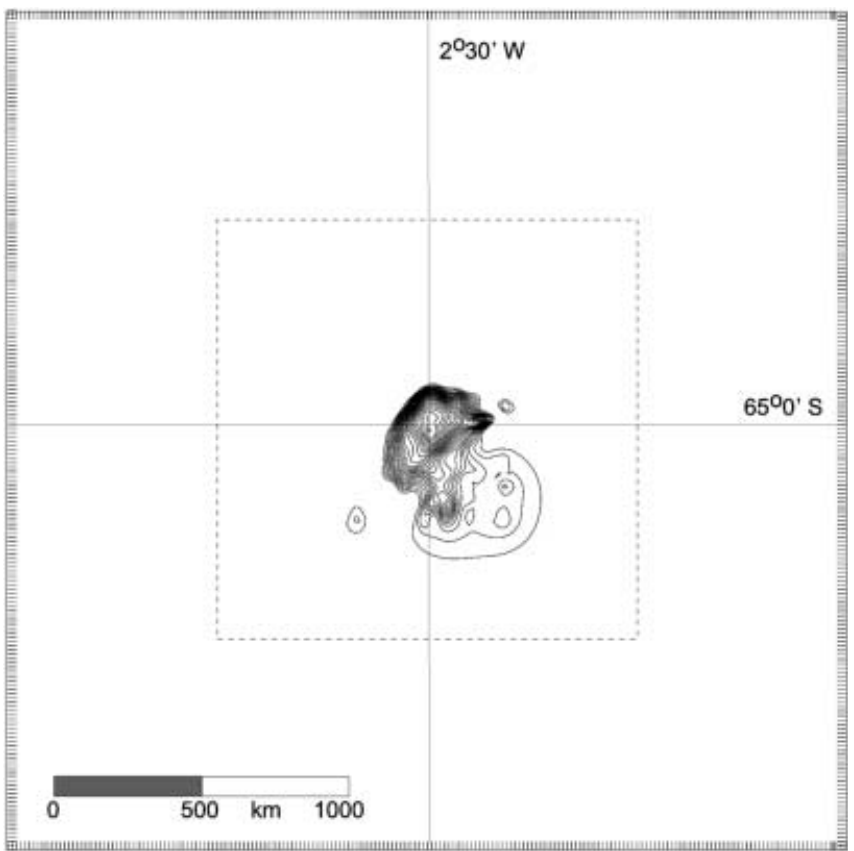

Fig. 6 Model domain, grid (indicated by tick marks) and topography of the Maud Rise model. The dashed square shows the area focusing on Maud Rise, shown in many of the following figures

choice of adaptive subgridscale parameterization schemes has proven well-suited for the ice-covered oceanic regime, and mesoscale variability caused by current instabilities is not the main issue of this study. The maximum slope $\left.(\nabla H)\right|_{\max }=6 \%$ in the model is close to observed gradients. The maximum value of $r=\nabla H / 2 H$ (Beckmann and Haidvogel 1993) is 0.06, and numerical errors due to the terrain-following coordinate transformation can be assumed negligible. In the vertical, 24 levels are used, with vertical grid stretching $(\theta=4.8$ in the notation of Song and Haidvogel 1994) used to increase resolution near the surface. For simplicity the Coriolis parameter is held constant at $f_{\mathrm{o}}=-1.32 \times 10^{-4} \mathrm{~s}^{-1}\left(65^{\circ} \mathrm{S}\right)$.

\subsubsection{Initialization and forcing}

The model is initialized with horizontally uniform profiles of potential temperature and salinity (see Fig. 7) and no flow. The stratification is taken from the Hydrographic Atlas of the Southern Ocean (Olbers et al. 1992), choosing the deep ocean northeast of Maud Rise as representative of the "undisturbed" ocean state. Thus, the initial state resembles the regional hydrography (Fig. 3) with its pronounced temperature and salinity maxima - except for the anomaly above the seamount.

The oceanic forcing is a combination of steady flow from the east, representing the southern (westwardflowing) limb of the Weddell Gyre and periodic tidal flow in this area. The amplitude of the steady and uniform far-field barotropic was chosen to be $1 \mathrm{~cm} \mathrm{~s}^{-1}$, following observations (Schröder and Fahrbach 1999) and the large-scale BRIOS simulations of Beckmann et al. (1999) and Timmermann et al. (2001). In addition, diurnal and semidiurnal tidal constituents were taken into account (with periods of one per day and two per day; we do not discriminate between $\mathrm{M}_{2}$ and $\mathrm{S}_{2}, \mathrm{~K}_{1}$ and $\mathrm{O}_{1}$. In this way, we ignore processes of fortnightly modulation of tides. These aspects must be postponed to future process studies.); the amplitudes taken from the tidal model described in sect. 3 . The total ocean forcing thus has a barotropic far-field zonal velocity of

$U(t)=U_{M}+U_{D} \sin \left(2 \pi \omega_{D} t\right)+U_{S D} \sin \left(2 \pi \omega_{S D} t\right)$.

In the reference experiment, the amplitudes are $U_{M}=$ $1.0 \mathrm{~cm} \mathrm{~s}^{-1}$, and $U_{D}=1.5 \mathrm{~cm} \mathrm{~s}^{-1}, U_{S D}=2.5 \mathrm{~cm} \mathrm{~s}^{-1}$ for the diurnal and semidiurnal frequencies, respectively (see also sect. 3).

Similarly to previous seamount studies (Haidvogel et al. 1993; Beckmann and Haidvogel 1997), the zonal mean mass transport streamfunction at the northern boundary was specified to result in steady or periodic barotropic flows through the domain. At the northsouth boundaries, however, an additional periodicity condition for perturbations from the zonal mean was enforced.
Fig. 7 Initial $T$ and $S$, and $N^{2}$ profiles according to the Hydrographic Atlas of the Southern Ocean (Olbers et al. 1992)
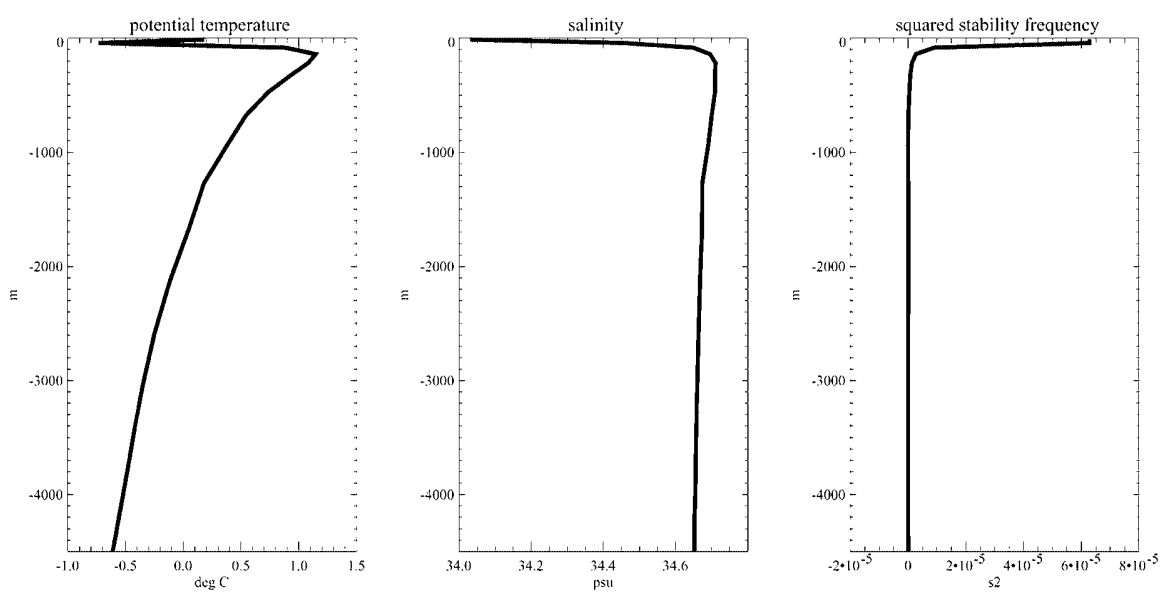
Atmospheric forcing consists of a constant wind of $2 \mathrm{~m} \mathrm{~s}^{-1}$ from the southeast, representing the generally off-shore winds in this region. Daily mean solar radiation and spatially uniform atmospheric temperatures are prescribed, beginning at $-4^{\circ} \mathrm{C}$ in May and varying sinusoidally to $-15^{\circ} \mathrm{C}$ in September. The dew point temperature is $2^{\circ}$ lower; precipitation is assumed to be zero. Again, the atmospheric forcing is uniform in space, such that any anomaly can be attributed to the topography.

With this forcing, the model is integrated for 180 days, beginning in May and comprising the main freezing period. To resolve the tides, the time step is set to $15 \mathrm{~min}$.

\section{The reference experiment}

The experiment described above serves as our reference case and we will describe its results in detail. Our main focus is anomalies in the sea-ice cover; however, we begin with the presentation of the oceanic fields.

\subsection{Oceanic response}

Oceanic flow around seamounts for steady or periodic forcing has been investigated in detail by Chapman and Haidvogel (1992); Haidvogel et al. (1993) and Beckmann and Haidvogel (1997). The combined effects of steady and tidal background currents have been considered by Goldner and Chapman (1997). In these papers, the physical and numerical parameter space has been explored in various directions. For the situation at Maud Rise (which is characterized by a moderate fractional seamount height of about 0.6, and a small Burger number due to the weak stratification), we therefore expect the development of a weak Taylor column as the response to the steady oceanic flow.

Since topographically trapped waves are possible for subinertial tidal frequencies, i.e. for diurnal tides poleward of $30^{\circ}$ geographical latitude, we also expect amplification of the diurnal tidal signal in form of seamount-trapped waves and, if non-linearity and complex topography permit, possibly some rectification of tidal energy to increase the doming of isopycnals above the topography. Semidiurnal tides may contribute to the overall variability in the region.

\subsubsection{Barotropic time-mean flow}

The vertically integrated time-mean oceanic circulation is only weakly influenced by the interaction with the sea ice. Under the prescribed steady and tidal forcing, the westward barotropic current splits at the seamount (Fig. 8). Due to the pronounced asymmetry and northsouth elongation of the topography, two counterrotating cells form; an anticyclonic Taylor column of $4 \mathrm{~Sv}$

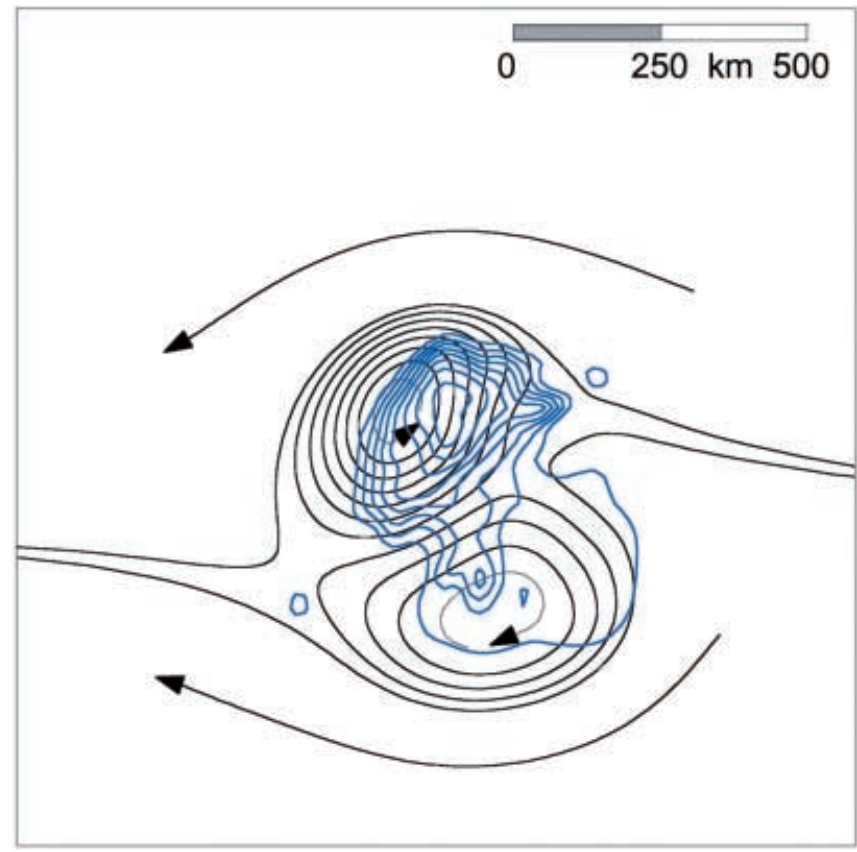

Fig. 8 Streamlines of time-mean barotropic flow in the center of the domain. Contour interval 0.5 Sverdrup

above the northern (higher) part of Maud Rise and a counterrotating cyclonic cell on the southern extension of the topographic obstacle. The centers of both cells are shifted downstream by the mean flow. The time-mean recirculating velocities as the combined result of steady impinging flow and tidal rectification reach $1.5 \mathrm{~cm} \mathrm{~s}^{-1}$.

\subsubsection{Tidal amplification and trapped waves}

Modelled tidal currents at Maud Rise reach about $9 \mathrm{~cm} \mathrm{~s}^{-1}$, i.e. they are enhanced only weakly (by a factor of about 2.5) relative to deep ocean values. This amplification is in qualitative agreement with the barotropic tidal model (see Sect. 3), indicating that our process model does represent the local structure of tidally induced flow at Maud Rise quite well. The relatively small tidal amplification is due to the fact that the tidal frequencies are not close to the resonance period of Maud Rise, being about 2-2.5 days (depending on the exact location; determined in a separate experiment not shown).

Snapshots of vertical velocity are used to illustrate the diurnal period topographic wave activity. Several dipoles of varying spatial scale can be identified, superimposed on and interfering with each other (Fig. 9). The dominant dipole is trapped to the northern topographic complex, with maximum vertical velocities along the steepest flanks (to the north of Maud Rise) of about 50 $\mathrm{m}$ day $^{-1}$. Additional dipoles are found at each small peak and submarine hill.

In the vertical, the weak stratification (see Fig. 7) allows the bottom-trapped waves to extend all through 


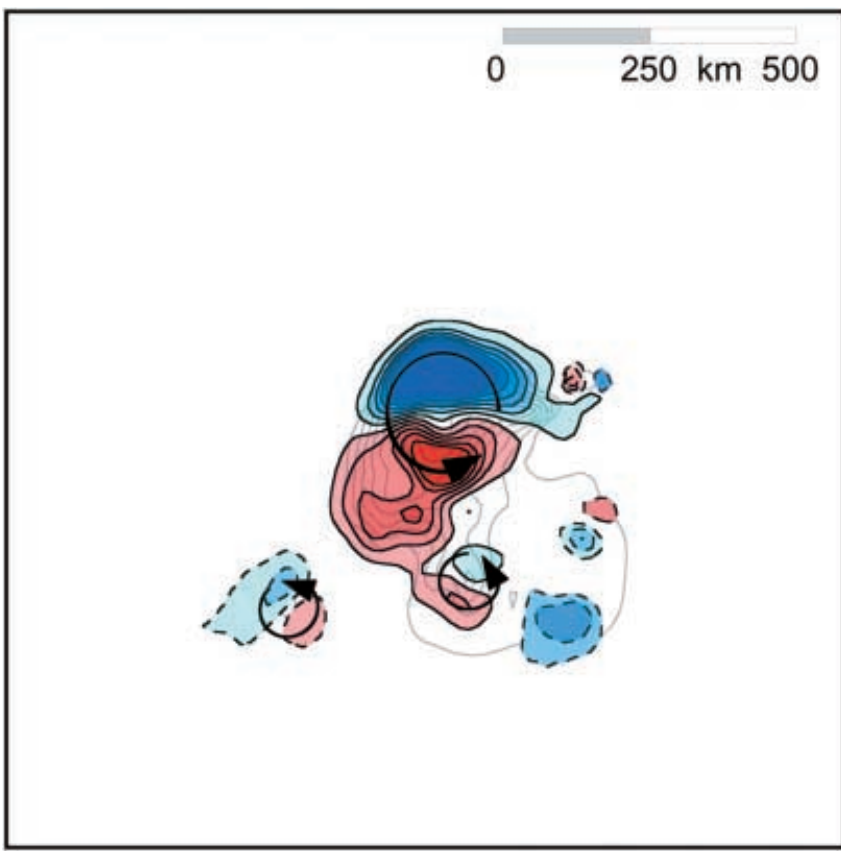

Fig. 9 Snapshot of the vertical velocity field near the bottom, illustrating the complex pattern of diurnal period seamount-trapped waves at Maud Rise. Upward (downward) motion is coloured red (blue). Contour interval: $5 \mathrm{~m} \mathrm{day}^{-1}$; dashed lines $0.5 \mathrm{~m} \mathrm{day}^{-1}$

the water column (Fig. 10), thus penetrating across the layer of maximum temperature at $250 \mathrm{~m}$ depth. The near-surface turbulence then mixes uplifted waters and leads to a net exchange of heat and salt between the ocean's interior and the surface mixed layer.

\subsubsection{Upper ocean fields}

Starting from horizontally uniform conditions, the thermal field above Maud Rise shows the typical area of reduced stability after only a few days (Fig. 10). This is a combined effect of the doming through Taylor cap generation and the enhanced mixing by the tidal currents, which is parameterized by adaptive (velocityand stability-dependent) eddy coefficients. Additional experiments show that the results are qualitatively insensitive to the exact form of the subgrid-scale closure scheme. The resulting mixed-layer anomaly closely resembles the climatological situation found in observations (see also Fig. 3). (Note, however, that our model does not represent different water masses on both sides of the seamount.)

The mid-depth doming found in the observations is not well represented by the model, because of the relatively coarse vertical resolution at depth. The choice of our model levels, however, was motivated by the need to resolve the surface boundary layer.

The discontinuity of the $T_{\max }$ layer above the seamount is not only a confirmation that the model is able to reproduce the observed situation at Maud Rise, but also necessary for the realistic simulation of the onset of ice formation, as will be shown in the next section.
Fig. 10 Meridional transect of the potential temperature field after 20 days of model integration. Contour interval $0.15{ }^{\circ} \mathrm{C}$. Superimposed is a snapshot of the vertical velocity illustrating the penetration of bottomintensified waves into the surface mixed layer. Contour interval: $5 \mathrm{~m} \mathrm{day}^{-1}$. Upward (downward) motion is shaded in red (blue)

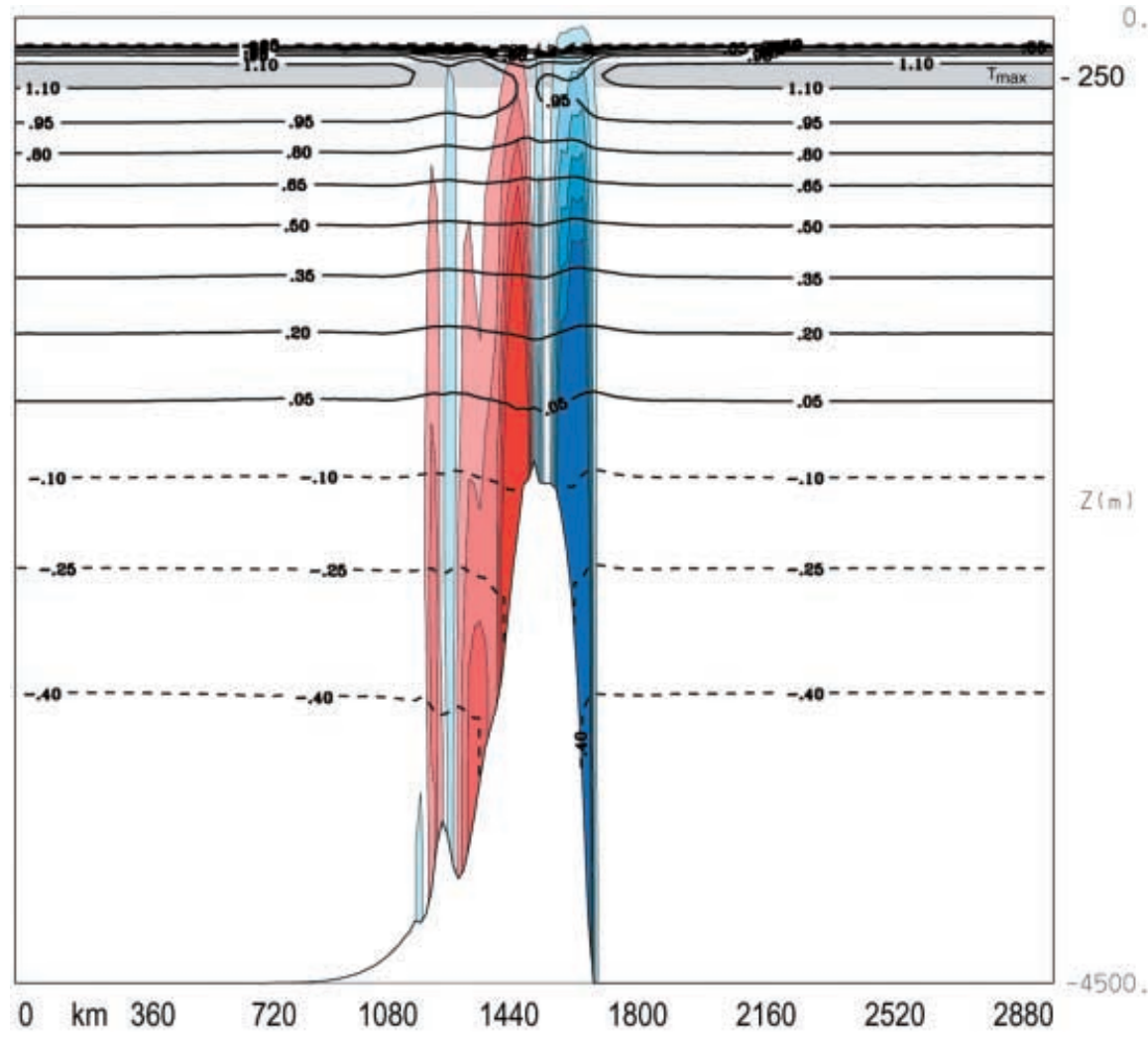


While the flow in the lower part of the water column becomes strictly periodic after 2 weeks of integration, the upper ocean/mixed layer evolves due to the combined effects of oceanic circulation and mixing, thermohaline fluxes during ice formation and the surface stress transmitted from the atmosphere to the ocean. As an example, the mixed-layer depth (defined as the depth of $0.01 \mathrm{~kg} \mathrm{~m}^{-3}$ potential density difference from the surface) is shown at day 80 of the integration (late July) in Fig. 11. At this time, the mixed layer is less than $140 \mathrm{~m}$ deep in undisturbed regions; the topographically induced deepening extends down to $240 \mathrm{~m}$ in an area that includes Maud Rise but is centered $200 \mathrm{~km}$ downstream of the seamount. This corresponds to a westward translation of about $2-3 \mathrm{~cm} \mathrm{~s}^{-1}$, caused by the wind stress with some contribution from the oceanic steady current. We will return to this issue below.

\subsection{Sea-ice response}

The evolution of the sea-ice cover at and downstream of Maud Rise is closely coupled to the dynamics of the upper ocean fields.

\subsubsection{Ice growth}

After 18 days of integration, the warm summer surface layer which is present in the initial fields has been cooled down by heat loss to the atmosphere and the formation of sea ice begins. By this time, the strength of the

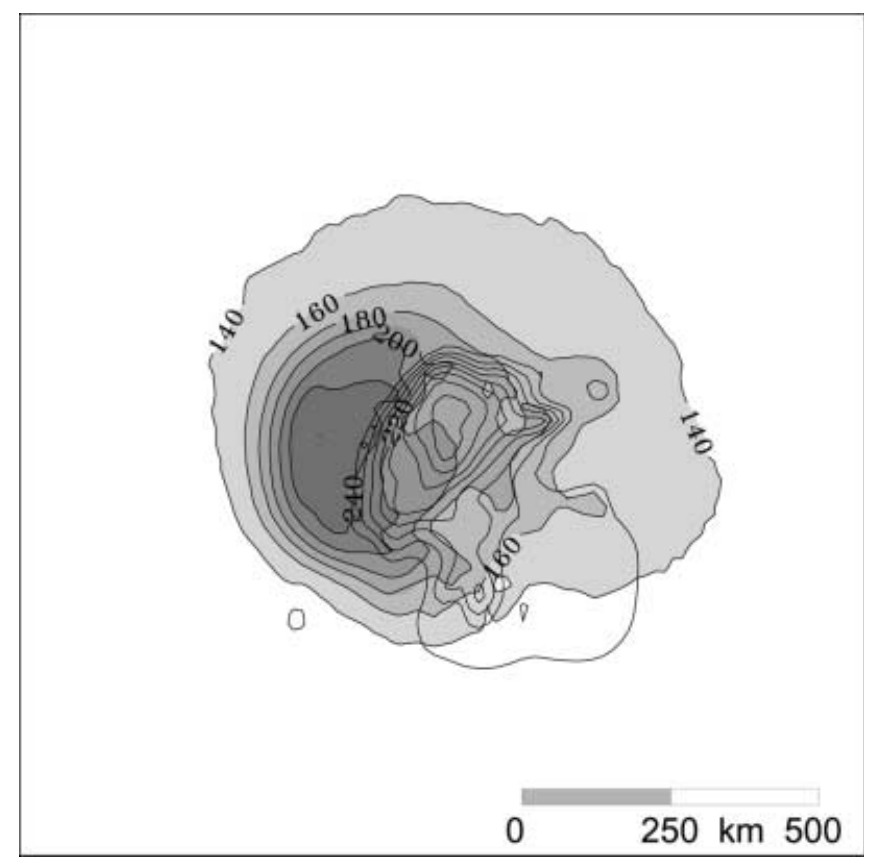

Fig. 11 Oceanic mixed layer depth in the center of the model domain two months after the first ice formation. Contour interval $20 \mathrm{~m}$. The maximum value is $250 \mathrm{~m}$ stratification above Maud Rise is significantly reduced. Consequently, sea-ice growth above Maud Rise is delayed because the brine release during the freezing process causes deeper convection in areas with a weaker stratification, which, in turn, leads to an increased heat flux to the surface and delayed freezing.

The overall evolution of the sea-ice cover is shown in Fig. 12. Within a month after first ice formation, about $80 \mathrm{~cm}$ of ice are formed thermodynamically, which is consistent with ULS (upward-looking sonar) observations along the Greenwich Meridian by Harms et al. (2001) and the coupled model simulation of Timmermann et al. (2001). At the beginning of July, the ice concentration has reached its maximum of about 0.9 for the domain-wide average.

Above Maud Rise, the sea-ice thickness in our central experiment reaches a maximum of only $50 \mathrm{~cm}$, which represents a reduction of local ice volume by roughly $30 \%$. The sea-ice volume in that area starts to decrease well before the seasonal melting begins (day 70; midJuly). While the ice thickness is significantly reduced, the ice concentration anomaly is less pronounced (Fig. 12).

\subsubsection{Ice cover}

A picture of the sea-ice thickness anomaly is presented in Fig. 13 for day 120, i.e. in early September, the time of minimum atmospheric temperature. By this time, the anomaly (defined by a $20 \%$ reduction of ice thickness) has grown to over $150000 \mathrm{~km}^{2}$ and has been advected westward at an average rate of $2.5 \mathrm{~cm} \mathrm{~s}^{-1}$. This is less than the drift that can be expected for a $2 \mathrm{~m} \mathrm{~s}^{-1}$ wind (approximately $2 \%$ of the wind velocity, relative to the ocean, in the case of free drift), and indicates that the
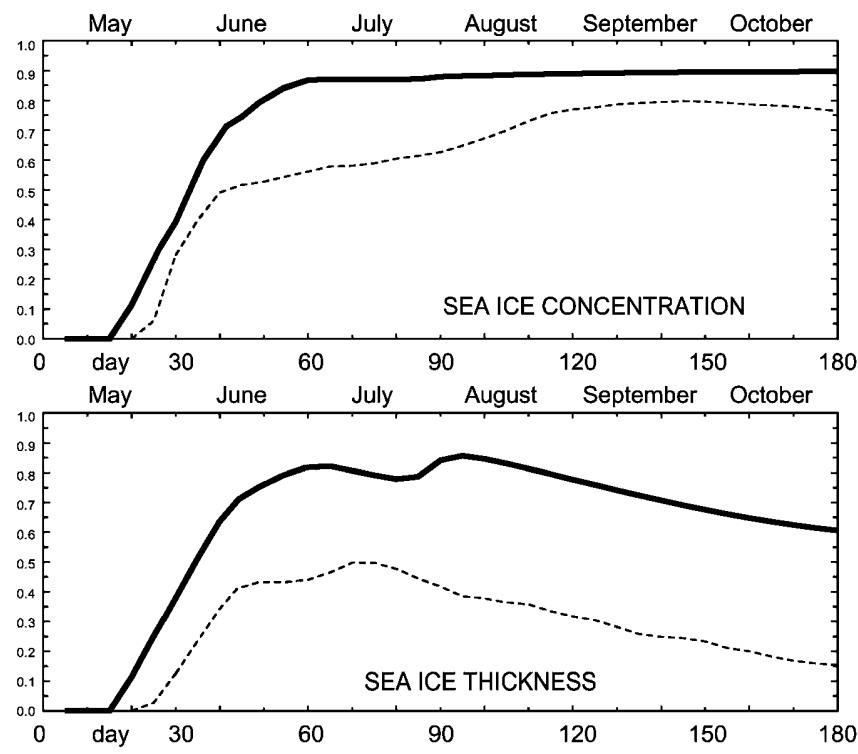

Fig. 12 Time series of sea-ice concentration (upper panel) and thickness (lower panel). The thick line represents the domain-wide mean, the dashed line shows the absolute minimum 


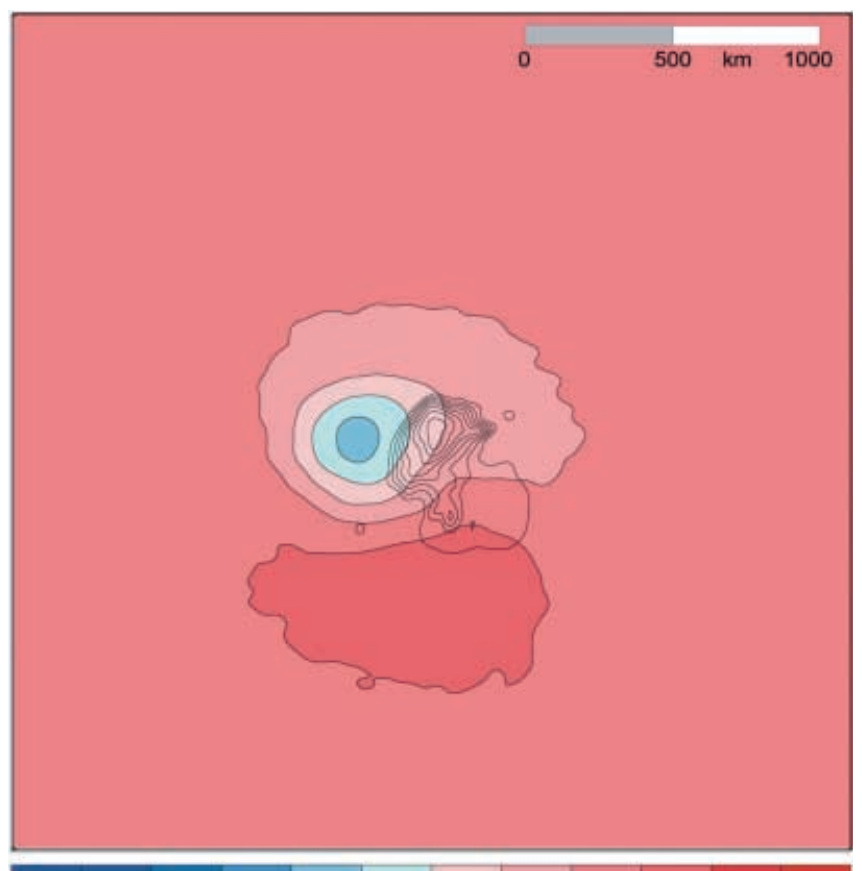

$\begin{array}{lllllllllll}0.0 & 0.1 & 0.2 & 0.3 & 0.4 & 0.5 & 0.6 & 0.7 & 0.8 & 0.9 & 1.0\end{array}$

Fig. 13 Ice thickness at day 120 (early September) in the reference experiment

translation of the anomaly and the individual ice drift velocities are not equal. We find that the daily and domain-wide average of the ice drift is $5.3 \mathrm{~cm} \mathrm{~s}^{-1}$ to the west and $0.8 \mathrm{~cm} \mathrm{~s}^{-1}$ to the north. This means that the ice drifts through the thickness anomaly and does not materially preserve it. The combined effects of ocean surface friction and Coriolis force lead to a deviation of about $37^{\circ}$ to the left of the (surface) wind direction.

On the other hand, the spatial variations in ice thickness cause a complex drift field because thinner ice is less subject to Coriolis deflection and thus moves more in the direction of the wind. In our model, three anomalous regions can be identified (Fig. 14): an area of divergent ice motion at the western flank of Maud Rise, an almost circular area of anomalous drift direction associated with the detached negative sea ice thickness anomaly and the area of southwestward drift of thicker ice south of Maud Rise.

\subsubsection{Evolution of the anomaly}

To illustrate the growth of the anomaly with time, Fig. 15 shows the evolution of the area of the sea-ice anomaly, again defined by a $20 \%$ reduction of ice thickness. (Note that the ice concentration field also reflects the ice-thickness variations, although with reduced amplitude.) The snapshots document how the anomaly begins to form on the downstream side of Maud Rise, temporarily assumes the shape of the 4000-m contour,

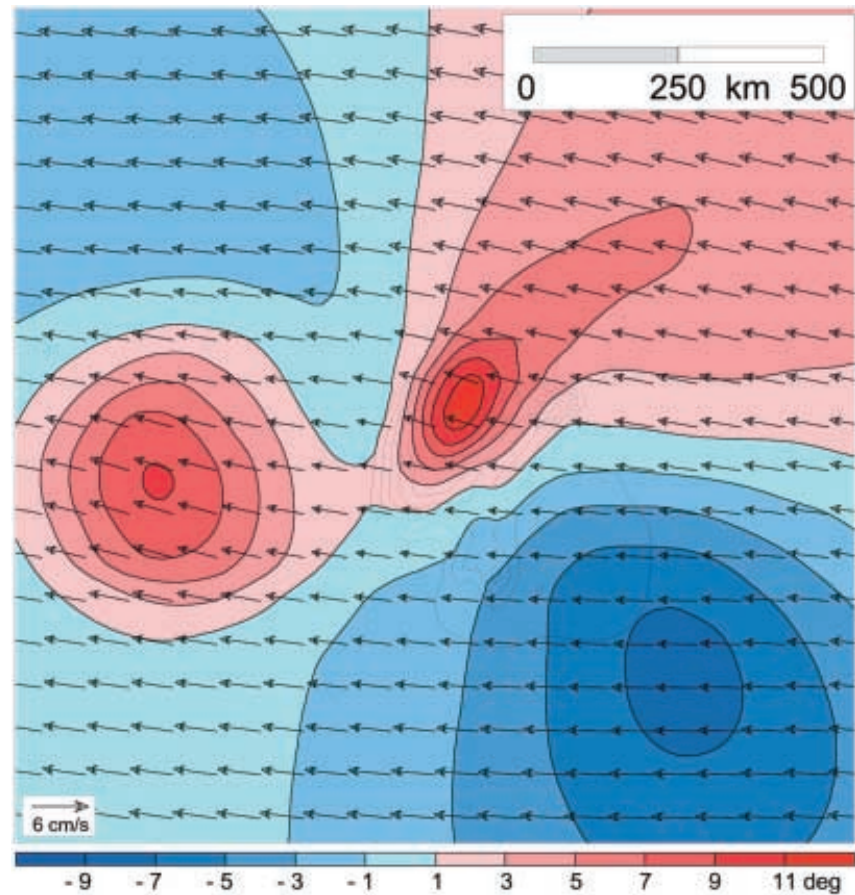

Fig. 14 Sea-ice drift vectors and direction at day 150 , averaged over a tidal cycle. Colors indicate clockwise (red) and anticlockwise (blue) deviation from the domain-wide mean. The clockwise rotation found west of Maud Rise corresponds to the area of thinner ice. Only every fifth vector is plotted
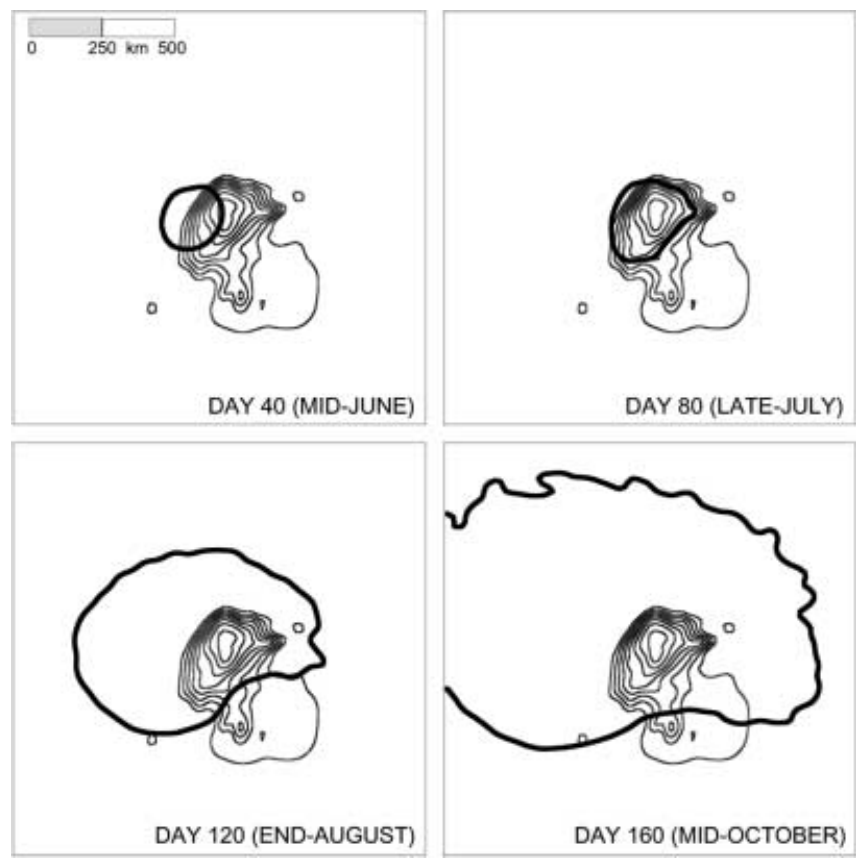

Fig. 15 A series of snapshots of the sea-ice anomaly, defined by a $20 \%$ difference in sea-ice thickness from the undisturbed surrounding. The plots cover the center of the model domain

and then, spreading laterally, extends mainly northwestward. The last picture shows that the influence of Maud Rise is regional rather than local. 


\section{Sensitivity studies}

This section presents the results of selected experiments, where individual mechanisms have been removed from or added to the model.

\subsection{No tidal forcing}

To elucidate the role of tides in the formation of the modelled sea-ice anomaly, we first switch off the tidal forcing. Changes in the circulation and water mass distribution include a much weaker Taylor column (only $0.25 \mathrm{~Sv}$ ), and weaker vertical mixing above the seamount. As a consequence, the oceanic flow remains mostly horizontal and the $T_{\max }$ layer remains largely intact across the seamount. The remaining large-scale flow divergence around Maud Rise, however, is much less effective in imprinting the topographic signature on the sea-ice fields and sea-ice thickness gradients are much smaller (Fig. 16a). An indication for the mainly dynamic reshaping of the sea-ice pack is that the area of ice reduction is accompanied by an area of increased ice thickness to the south.

We conclude that tidal flow creates an effective and important mechanism to generate negative sea-ice anomalies in the Maud Rise area. Even though the tidal currents are relatively weak, and their amplification at the seamount is only moderate, the enhanced level of variability is crucial in breaking up the stratification,
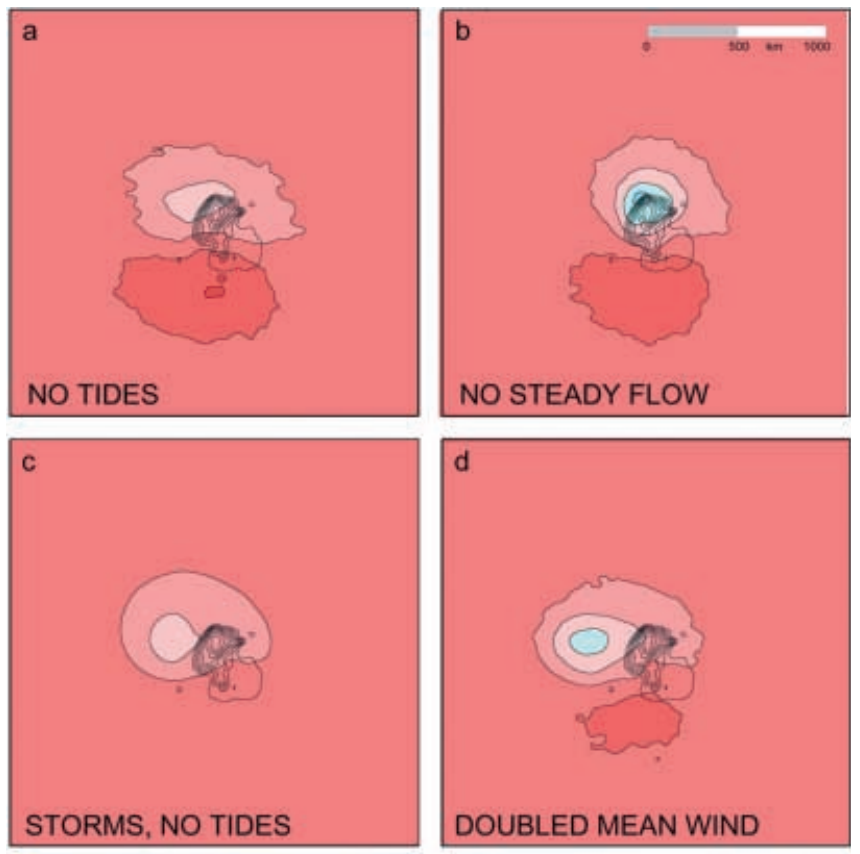

$\begin{array}{lllllllllll}0.0 & 0.1 & 0.2 & 0.3 & 0.4 & 0.5 & 0.6 & 0.7 & 0.8 & 0.9 & 1.0\end{array}$

Fig. 16a-d Sea-ice thickness anomaly at day 120 (to be compared to Fig. 13) in experiments with a steady ocean forcing only, b no oceanic mean flow, $\mathbf{c}$ no tides but periodic storms and $\mathbf{d}$ stronger mean wind while the rectified residual flow produces a quasipermanent surface divergence.

Further experiments show that the contributions of diurnal and semidiurnal tides to the sea-ice anomaly are similar in strength. The diurnal component, although smaller in amplitude, generates the strong lee-side surface flow divergence; the semidiurnal constituents contribute to the overall variability. Only the combined effect leads to significant manifestations in the sea-ice cover as seen in Figs. 13-15.

\subsection{No steady oceanic flow}

If the steady oceanic forcing is switched off, the tidally induced anomaly remains in the immediate vicinity of the seamount (Fig. 16b), despite the steady southeasterly wind. Apparently, the oceanic mean flow is responsible for the separation of the mixed layer (and sea-ice anomalies) from the topography.

This experiment, in combination with the reference and the previous "no tides" cases, reveals the complex interaction between wind, steady and periodic ocean currents. Each of these forcings is responsible for some aspect of the coupled ice-ocean dynamics: the generation of the sea-ice and mixed-layer anomalies (tides), their separation from the topography (oceanic mean flow), and the westward translation of the sea ice (wind).

\subsection{Oscillatory wind variability}

Having found that variability plays a crucial role, one might ask whether variable winds might have a similar effect. In a third sensitivity experiment, we replaced the tides by a temporally varying wind (the steady oceanic flow is maintained). Spatial uniform storms blowing north-south with a time-dependence of the form

$V(t)=V_{S} \sin ^{3}\left(2 \pi \omega_{S} t\right)$

were used, with $V_{S}=20 \mathrm{~m} \mathrm{~s}^{-1}$, and $\omega_{S}^{-1}=10$ days. In the 10-day mean, the effect on sea ice is rather small; we find a similarly weak anomaly as in the experiment with steady oceanic flow only (Fig. 16c).

We argue that this can be explained by the fact that synoptic wind variations do not affect the deeper layers of the ocean and thus do not create sufficient vertical motion to erode the thermocline. Each storm will move the sea-ice pack $50 \mathrm{~km}$ off the topography, not enough to generate a much larger area of reduced sea-ice thickness.

\subsection{Increased steady wind}

Finally, a series of experiments was conducted to investigate the dependence of the solution on the strength of the steady wind (between 2 and $5 \mathrm{~m} \mathrm{~s}^{-1}$ ). An example is given for doubled steady-wind amplitude 
(Fig. 16d). We find that the picture remains the same qualitatively under a wide range of parameter variation. However, the sea-ice anomaly is advected westward more rapidly by stronger wind. In all cases (including the reference experiment), it moves faster than the oceanic mixed-layer anomaly, which mainly moves with the steady oceanic flow. Figure 17 shows the separation of sea-ice anomaly and mixed-layer anomaly on their westward translation away from the Maud Rise.

\section{Summary and discussion}

We have conducted a series of semi-idealized numerical experiments to identify and quantify the effect of processes at Maud Rise on the sea-ice cover. Realistic attributes of the model configuration are the local topography, typical forcing amplitudes and directions, as well as the ambient stratification.

Forcing was idealized such that any deviation from uniformity can be attributed to the effect of the seamount. The main results are:

- Tidally induced flow at Maud Rise leads to a local preconditioning of the upper water column, with increased upward oceanic heat flux. This causes a pronounced reduction of the sea-ice volume in the area.

- The region of reduced sea-ice volume moves downstream as the result of wind and steady oceanic flow; it ultimately separates from the mixed-layer anomaly.

- The mixed-layer anomaly also does not remain attached to the topography, but moves downstream with the steady oceanic flow.

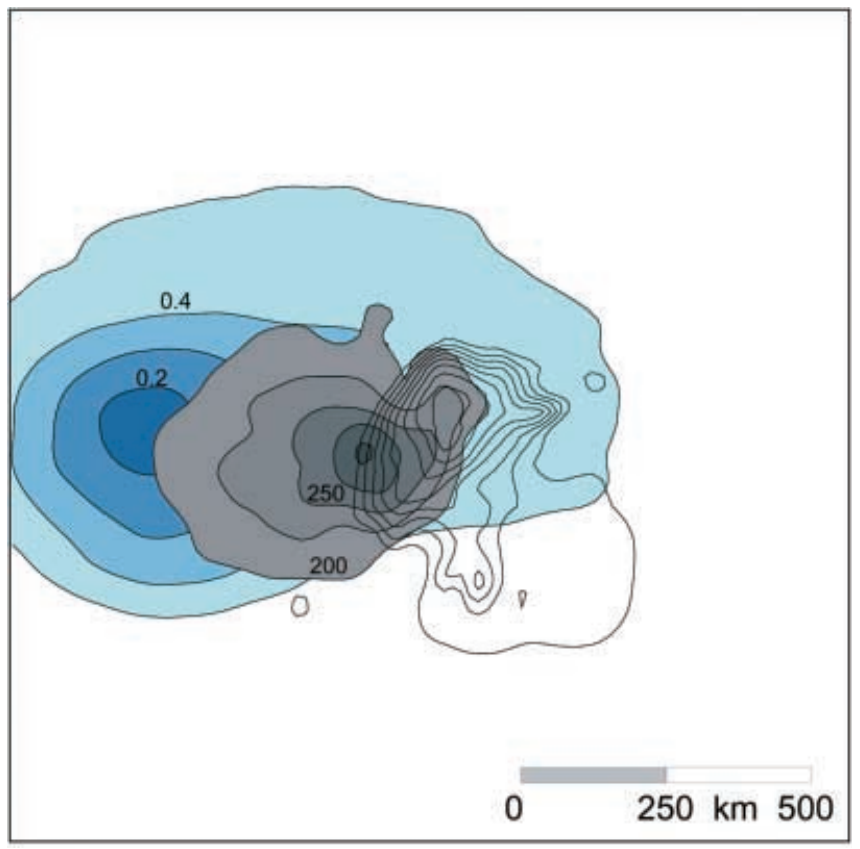

Fig. 17 Sea-ice thickness anomaly and mixed-layer depth in the experiment with doubled wind forcing (day 150)
These results hold for a wide range of physical and numerical parameter choices. Direction and strength of atmospheric and oceanic forcing can be changed within reasonable limits, without affecting our basic conclusions. Variations in vertical mixing (as long as it does not lead to open-ocean deep convection everywhere in the domain), lateral mixing and internal ice model parameters do not qualitatively change the results. Of course, the specific combination of parameters will influence the sea-ice growth, but not the occurrence, relative strength and translation of the anomaly.

Although we have used the Weddell Polynya of 1974 1976 as a motivation for this study, we are well aware that our reduced sea-ice thickness and concentration cannot be directly compared to this extreme event. However, compared to the ambient ocean, the region near Maud Rise regularly features a relatively thin seaice cover (Harms et al. 2001) with intermittent polynyas (e.g. Gordon and Comiso 1988); this is the area where the Weddell Sea ice starts to break up in spring (Gloersen et al. 1992). We believe that the processes investigated in this paper are responsible for the observed minimum in ice volume. While previous investigations of the Weddell Polynya mainly aimed at the explanation of a (so far) singular anomaly, our study provides an explanation for the observed "climatological" regional thinning of the sea-ice cover near Maud Rise.

In contrast to mechanisms discussed by Martinson et al. (1981); Lemke (1987); Lemke et al. (1990) or Timmermann et al. (1999), preconditioning of the water column for polynya formation in our experiments is not associated with a shallow mixed layer. In their models, with reduced ocean dynamics, the creation of static instability through salt enrichment in a shallow mixed layer is the only mechanism that can lead to enhanced vertical mixing and increased heat transfer. The inclusion of tides in a primitive equation ocean model, however, provides a source of enhanced mixing from the ocean's interior - so that negative sea-ice volume anomalies are generated even with an anomalously deep mixed layer.

Finally, our findings have implications for ocean climate models, which usually neglect tidal forcing and therefore miss an important mechanism for generating areas of enhanced variability, not only at seamounts but also on shallow shelves.

\section{Outlook}

Our experiments were conducted with a simplified uniform forcing. In reality, spatial atmospheric and oceanic variability, the proximity of the Antarctic coast and inhomogeneities arriving from upstream will lead to a more complicated picture, where the anomaly might be not as obvious as in our idealized experiments. However, we believe that the modelled processes of ice-ocean interaction will occur regularly every fall and winter. It seems conceivable that in some years, under favorable large-scale (atmospheric or oceanic) circumstances, the 
effects may be enhanced and lead to the formation of a polynya, as observed in the mid-1970s.

Such a large-scale situation might be set by a phenomenon identified by Beckmann and Timmermann (2001), called the Antarctic circumpolar coastal wave (ACCW). This long-period, westward-propagating bottom-temperature signal seems to change the typical stratification by increasing the temperature of the upwelled water masses for several consecutive years.

Effects of interannual variability (both of atmospheric forcing and/or oceanic ambient situations) and the feed-back between fortnightly tidal modulation and sea-ice formation will have to be investigated separately. Ultimately, active coupling to an atmosphere seems necessary to fully understand the air-sea interaction in ice-covered oceans.

Acknowledgements Helpful comments by two anonymous reviewers and motivating discussions with members of the BRIOS team are gratefully acknowledged.

\section{References}

Alverson K (1997) Mechanisms for lateral exchange with oceanic convection sites. J Phys Oceanogr 27: 1436-1446

Alverson K, Owens WB (1996) Topographic preconditioning of open-ocean convection. J Phys Oceanogr 26: 2196-2213

Andersen OB, Woodworth PL, Flather RA (1995) Intercomparison of recent tide models. J Geophys Res 100: 25261-25282

Beckmann A, Haidvogel DB (1993) Numerical simulation of flow around a tall isolated seamount: Part I: Problem formulation and model accuracy. J Phys Oceanogr 23: 1736-1753

Beckmann A, Haidvogel DB (1997) A numerical simulation of flow at Fieberling Guyot. J Geophys Res 102: 5595-5613

Beckmann A, Timmermann R (2001) Circumpolar influences on the Weddell Sea: indication of an Antarctic circumpolar coastal wave. J Clim (in press)

Beckmann A, Hellmer HH, Timmermann R (1999) A numerical model of the Weddell Sea: large-scale circulation and water mass distribution. J Geophys Res 104: 23375-23391

Bersch M, Becker GA, Frey H, Koltermann KP (1992) Topographic effects of the Maud rise on the stratification and circulation of the Weddell Gyre. Deep Sea Res 39: 303-331

Boyer DL, Zhang X (1990) Motion of oscillatory currents past isolated topography. J Phys Oceanogr 20: 1425-1448

Brink KH (1989) The effect of stratification on seamount-trapped waves. Deep Sea Res 36: 825-844

Brink KH (1990) On the generation of seamount-trapped waves. Deep Sea Res 37: 1569-1582

Brink KH (1995) Tidal and lower frequency currents above Fieberling Guyot. J Geophys Res 100: 10817-10832

Carsey FD (1980) Microwave observations of the Weddell Polynya. Monthly Weather Rev 108: 2032-2044

Chapman DC (1989) Enhanced subinertial diurnal tides over isolated topographic features. Deep Sea Res 36: 815-824

Chapman DC, Haidvogel DB (1992) Formation of Taylor caps over a tall isolated seamount in a stratified ocean. Geophys Astrophys Fl Dyn 64: 31-65

Codiga DL (1993) Laboratory realizations of stratified seamounttrapped waves. J Phys Oceanogr 23: 2053-2071

Codiga DL, Eriksen CC (1997) Observations of low-frequency circulation and amplified subinertial tidal currents at Cobb seamount. J Geophys Res 102: 22993-23007

Cornillon P (1986) The effect of the New England Seamounts on Gulf Stream meandering as observed from satellite IR imagery. J Phys Oceanogr 16: 386-389
Defant A (1940) Die ozeanographischen Verhltnisse whrend der Ankerstation des "Altair" amd Nordrand des Hauptstromstriches des Golfstromes nördlich der Azoren. Ann Hydr Mar Meteor, 68: Beiheft

Egbert GD, Bennett HAF, Foreman MGG (1994) TOPEX/POSEIDON tides estimated using a global inverse model. J Geophys Res 99: 24821-24852

Eriksen CC (1991) Observations of amplified flows atop a large seamount. J Geophys Res 96: 15227-15236

Eriksen CC (1998) Internal wave reflection and mixing at Fieberling Guyot. J Geophys Res 103: 2977-2994

Genco ML, Lyard F, Le Provost C (1994) The oceanic tides in the South Atlantic Ocean, Annales Geophysicae 12: 868-886

Genin A, Boehlert GW (1985) Dynamics of temperature and chlorophyll structures above a seamount: an oceanic experiment. J Mar Res 43: 907-924

Genin A, Noble M, Lonsdale PF (1989) Tidal currents and anticyclonic motions on two North Pacific seamounts. Deep Sea Res 36: 1803-1815

Gloersen P, Campbell WJ, Cavalieri D, Comisco JC, Zwally HJ, Parkinson CL (1992) Arctic and antarctic sea ice, 1978-1987: satellite passive-microwave observations and analysis. NASA special publication, SP-511; Washington, DC, $290 \mathrm{pp}$

Goldner DR, Chapman DC (1997) Flow and particle motion induced above a tall seamount by steady and tidal background currents. Deep Sea Res 44: 719-744

Gordon AL (1982) Weddell deep water variability. J Mar Res 40: 199-217

Gordon AL, Huber BA (1984) Thermohaline stratification below the southern ocean sea ice. J Geophys Res 89: 641-648

Gordon AL, Comiso JC (1988) Polynyas in the Southern Ocean. Scientific American 258: 70-77

Haidvogel DB, Wilkin JL, Young RE (1991) A semi-spectral primitive equation ocean circulation model using vertical sigma and orthogonal curvilinear horizontal coordinates. J Comput Phys 94: 151-184

Haidvogel DB, Beckmann A, Chapman DC, Lin R-Q (1993) Numerical simulation of flow around a tall isolated seamount: Part II: Resonant generation of trapped waves. J Phys Oceanogr 23: 2373-2391

Harms A, Fahrbach E, Strass VH (2001) Ice transports in the Weddell Sea. J Geophys Res 106: 9057-9073

Hibler WD III (1979) A dynamic-thermodynamic sea ice model. J Phys Oceanogr 9: 815-846

Hogg NG (1980) Effects of bottom topography on ocean currents. In: Hide R, White PW (eds) Orographic effects in planetary flows GARP Publication Series 23: 167-205

Huthnance JM (1974) On the diurnal tidal currents over Rockall Bank. Deep Sea Res 21: 23-35

Hunkins K (1986) Anomalous diurnal tidal currents on the Yermak Plateau. J Mar Res 44: 51-69

Jackett DR, McDougall TJ (1995) Stabilization of hydrographic data. J Atmos Oceanic Technol 12: 381-389

Kim S-J, Stössel A (2001) The impact of subgrid-scale convection on global thermohaline properties and circulation. J Phys Oceanogr 31: 656-674

Kunze E, Toole JM (1997) Tidally driven vorticity, diurnal shear, and turbulence atop Fieberling seamount. J Phys Oceanogr 27: 2663-2693

Lemke P (1987) A coupled one-dimensional sea ice-ocean model. J Geophys Res 92: 13164-13172

Lemke P, Owens WB, Hibler WD III (1990) A coupled sea ice mixed-layer - pycnocline model for the Weddell Sea. J Geophys Res 95: 9513-9525

Marsland SJ, Wolff J-O (2001) On the sensitivity of Southern Ocean sea ice to the surface freshwater flux: a model study. J Geophys Res 106: 2723-2741

Martinson DG (1990) Evolution of the Southern Ocean winter mixed layer and sea ice; open-ocean deep-water formation and ventilation. J Geophys Res 95: 11641-11654

Martinson DG, Killworth PD, Gordon AL (1981) A convective model for the Weddell Polynya. J Phys Oceanogr 11: 466-487 
Meincke J (1971) Observations of an anticyclonic vortex trapped above a seamount. J Geophys Res 76: 7432-7440

Muench RD, Morison JH, Padman L, Martinson D, Schlosser P, Huber B, Hohmann R (2001) Maud rise revisited. J Geophys Res 106: $2423-2440$

Olbers DJ, Gouretski V, Sei G, Schröter J (1992) Hydrographic atlas of the Southern Ocean. AWI, Bremerhaven, $82 \mathrm{pp}$

Parkinson CL, Washington WM (1979) A large-scale numerical model of sea ice. J Geophys Res 84: 311-337

Pacanowski RC, Philander SGH (1981) Parameterization of vertical mixing in numerical models of tropical oceans. J Phys Oceanogr 11: 1443-1451

Richardson PL (1981) Gulf Stream trajectories measured with free drifting buoys. J Phys Oceanogr 11: 999-1010

Robertson R, Padman L, Egbert GD (1998) Tides in the Weddell Sea. In: Jacobs SS, Weiss RF (eds) Ocean, Ice, and Atmosphere Antarctic Res. Ser. 75, AGU, Washington DC. pp. 341-369

Roden GI (1987) Effect of seamounts and seamount chains on ocean circulation and thermohaline structure. In: Keating B, Fryer P, Batiza R, Boehlert G (eds) Seamounts, islands and atolls Geophysical Monograph 43 American Geophysical Union, Washington, DC. pp. 335-354

Roden GI, Taft BA (1985) Effect of the Emperor seamounts on the mesoscale thermohaline structure during the summer of 1982. J Geophys Res 90: 839-855

Schröder M, Fahrbach E (1999) On the structure and the transport of the eastern Weddell Gyre. Deep Sea Res 46: 501-527
Semtner AJ (1976) A model for the thermodynamic growth of sea ice in numerical investigations of climate. J Phys Oceanogr 63: 79-389

Smith WHF, Sandwell DT (1997) Global sea-floor topography from satellite altimetry and ship depth soundings. Science 277: 1956-1962

Song Y, Haidvogel DB (1994) A semi-implicit ocean circulation model using a generalized topography-following coordinate. J Comput Phys 115: 228-244

Timmermann R, Lemke P, Kottmeier Ch (1999) Formation and maintenance of a polynya in the Weddell Sea. J Phys Oceanogr 29: $1251-1264$

Timmermann R, Beckmann A, Hellmer HH (2001) Simulation of ice-ocean dynamics in the Weddell Sea. Part I: Model configuration and validation. J Geophys Res (in press)

UNESCO (1981) Tenth report of the joint panel on oceanographic tables and standards. UNESCO technical papers in marine science 36, UNESCO, Paris

van den Broeke M (2000) On the interpretation of Antarctic temperature trends. J Climate 13: 3885-3889

Vastano AC, Warren BA (1976) Perturbation of the gulf stream by Atlantic II seamount. Deep Sea Res 23: 681-694

Whitworth T, Nowlin WD (1987) Water masses and currents of the Southern Ocean at the Greenwich meridian. J Geophys Res 92: 6462-6476

Zhang X, Boyer DL (1993) Laboratory study of rotating, stratified, oscillatory flow over a seamount. J Phys Oceanogr 23: 1122-1141 